\title{
A Cheap, Efficient Nebuliser for use at Home
}

\author{
Major I D Evans* \\ MRCP, RAMC
}

Senior Specialist in Paediatrics, Cambridge Military Hospital, Aldershot

\section{Dr Catrina Griffiths DCH, DTM \& H}

British Military Hospital, Rinteln, BFPO 29

SUMMARY: Electric nebulisers are expensive. We assessed a cheap, foot operated pump and nebuliser and found that it was efficient and easy to use.

\section{Introduction}

Nebulised Salbutamol and sodium cromoglycate are often used at home to treat asthma in children. Parents may like to buy their nebuliser, but electric models are expensive. We carried out an assessment of the Easyair Nebuliser to see if it was suitable for use at home. The Easyair Nebuliser is a plastic footpump (similar to a car footpump) with an integral bacterial filter. Complete with tubing, nebuliser and facemask it costs about $£ 25$ and weighs $1.64 \mathrm{~kg}$.

\section{Method}

1. The footpump was connected to an Inspiron Minineb Nebuliser with a $217 \mathrm{~cm}$. length of plastic tubing of $4 \mathrm{~mm}$ internal diameter. A Wrights respirometer was connected to the outlet of the Minineb Nebuliser. The flowrate through the system at a stepping rate of $40 /$ minute was measured, using 4 different Minineb Nebulisers. We chose 40 steps/mins. because this was a rate that a young woman (CG) could achieve comfortably.

2. The time taken to nebulise water, Intal Nebuliser solution and Ventolin Respirator solution was measured. A paediatric facemask was attached to the outlet of the Minineb Nebuliser. The dry Minineb Nebuliser and facemask were weighed on a Sartorius 1212 MP Dualrange Digital Balance using the 0-300 G range. $2 \mathrm{mls}$. of fluid were put in the Minineb and the Minineb and facemask reweighed. The nebuliser was connected to the footpump and air was delivered using a stepping rate of $40 /$ minute. The nebuliser was held still during the nebulisation.

The time taken to nebulise the fluid was measured. The end point was taken after 30 seconds without visible aerosol being produced. At the end of nebulisation, the Minineb Nebuliser and facemask were weighed again. The weight and percentage of fluid nebulised were calculated. We assumed that the specific gravity of all the liquids was 1.0; the error introduced was small.

\section{Results}

The airflow through the nebuliser at 40 steps per minute was 5.16-5.96 1/min (mean: $5.61 / \mathrm{min}$.)

The time taken to nebulise $2 \mathrm{mls}$ of water was 5.5-7.75 mins (mean: $7.06 \mathrm{mins}$ ). The volume nebulised was 0.75 $1.02 \mathrm{mls}(38-51 \%)$ mean $0.89 \mathrm{mls}(44 \%)$.

The time taken to nebulise $2 \mathrm{mls}$ of Intal Nebuliser solution was 7.0-8.25 mins (mean: 7.63). The volume nebulised was $0.76-0.99 \mathrm{mls}(39-54 \%)$ mean: $0.91 \mathrm{mls}$ $(47 \%)$.

The time taken to nebulise $2 \mathrm{mls}$ of Ventolines Respirator Solution was 5.5-7.0 mins (mean: 6.13 mins). The volume nebulised was $0.87-1.28 \mathrm{mls}(42-63 \%)$, mean: $1.01 \mathrm{mls}(49 \%)$.

\section{Discussion}

Our results show that the Easyair Nebuliser (Fig 1) is almost as efficient as gas from a cylinder. The meang nebulisation time and dead volume (volume remaining after nebulisation) are similar to those obtained by Clay et al using compressed air ${ }^{1}$. Using the absence of visible aerosol production for 30 seconds as an endpoint produced variable results. i.e. we found that a constant aerosol was produced for 4.5-5 minutes, until all the liquid in the bottom of the chamber had been nebulised, and after this aerosol production was intermittent, depending on the chance fall of droplets to the bottom of the chamber. The airflow produced by the footpump should produce an aerosol with a median diameter of 6$10 \mu \mathrm{m}$ and result in only about $40 \%$ of the droplets having a diameter of less than $5 \mu \mathrm{m}$, (the optimum size for droplet deposition in the lungs). However it has been shown that this does not adversely affect the clinical response ${ }^{3}$. Indeed it is our experience that the footpump produces a clinically effective aerosol. The Easyair Nebuliser is much cheaper than an electric nebuliser, making it suitable for poorer families. It is mechanically simple, robust and reliable, and can be easily taken on holiday. The effort needed to operate it is within the capacity of most young women, the group most likely to use it.

\section{REFERENCES}

1 CLAY M M et al Assessment of jet nebulisers for lung 
aerosol therapy. Lancet 1983; ii: 592-594.

2 Clay M M et al. Factors influencing the size distribution of aerosols from jet nebulisers. Thorax 1983; 38:
3 Douglas, $\mathbf{J} \mathbf{G}$ et al. Is the flowrate used to drive a je nebuliser clinically important $B r$ Med J 1985; 290: 29.

$755-759$.
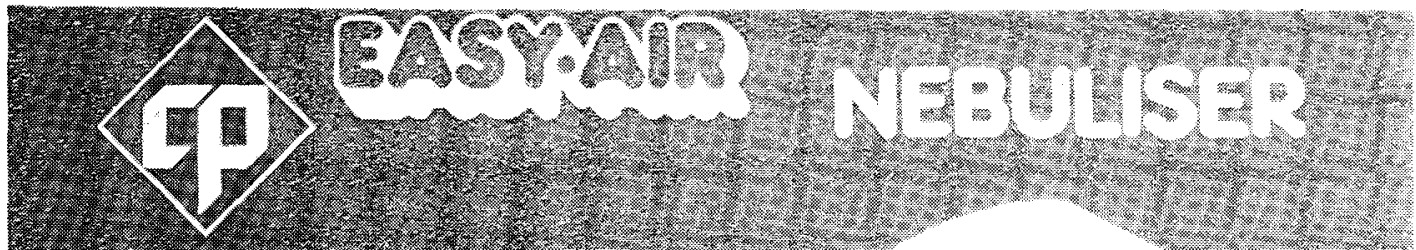

Compos Fortise: $2=5 \times 1008=$
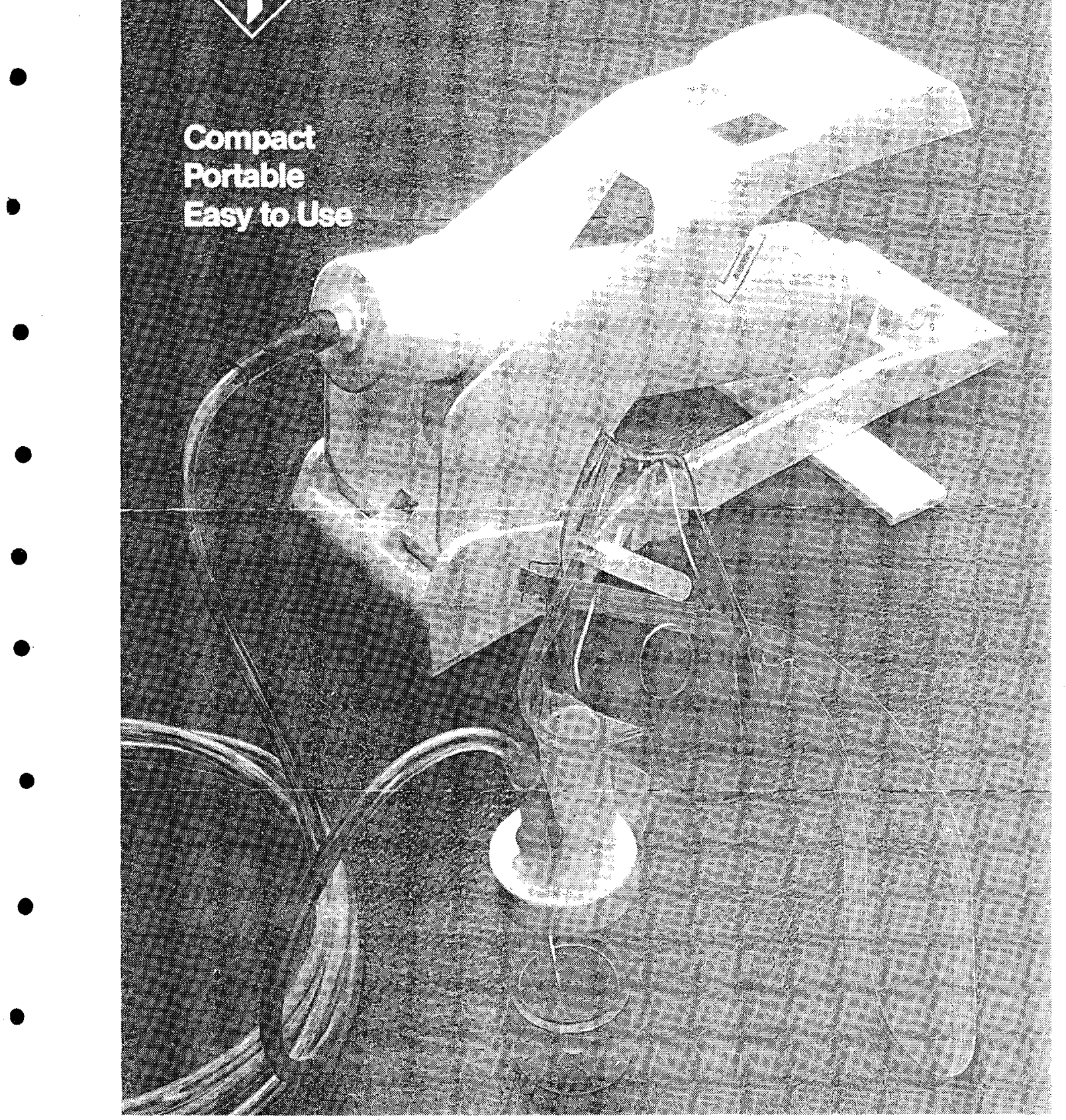